\title{
Plant vs. Animal, Which is the Most Prefer Understanding of Evolution?
}

\author{
Hana Gardenia Mahbubah ${ }^{1}$, Topik Hidayat ${ }^{2}$, Bambang Supriatno $^{3}$ \\ ${ }^{1}$ Master of Biology Education Study Program, Universitas Pendidikan Indonesia (UPI). Jl. Dr. \\ Setiabudi 229, Bandung, 40154, Indonesia \\ ${ }^{2,3}$ Department of Biology Education, Universitas Pendidikan Indonesia (UPI). Jl. Dr. Setiabudi \\ 229, Bandung, 40154, Indonesia \\ ${ }^{2}$ Email: topikhidayat@upi.edu
}

\begin{abstract}
Evolution is one of the main subjects of biology taught in science colleges. Unfortunately, students seem less attention to this subject. In the subject of evolution, the lesson commonly uses the animal as a model to improve the students understanding. The purpose of this study is to compare the ability of tree thinking students who use animals and plants as a model in the evolution lesson. Tree thinking refers to an approach to evolution that emphasizes reading and interpreting phylogenetic tree. This study involved 20 undergraduate students enrolled in the evolution course for biology majors at Universitas Pendidikan Indonesia (UPI). The tree thinking ability of students was measured using Tree Thinking Concept Inventory (TTCI) of Naegle with a little modification. In this test, we analyzed student preferences using animal or plant models using phylogenetic tree diagrams. Results showed that students' TTCI score was higher when using animal models $(65.42 \%)$ than plant models $(55 \%)$. These results suggested that students remain to prefer animal models compare to plant models to study evolution. Nevertheless, the use of plants as models can be an alternative to learning evolution in the future.
\end{abstract}

Keyword : Tree thinking, TTCI, Plant vs Animal, Evolution

\section{Introduction}

Taxonomy and evolution become the most important part of the curriculum in Indonesia from elementary school to college with various modifications tailored to the intellectual development of students [1]. Many factors cause students to be uninterested in learning evolution; most students assume that evolution is a theoretical lesson material that requires rote so that less attention to students and the process of evolution is difficult to prove the truth. Surveys consistently report low levels of understanding and acceptance of evolution in the United States [2]. Unlike the 32 European countries and Japan, however, the proportion of evolutionary acceptance is higher in the country. The acceptance of evolution is lower in the United States than in Japan or Europe, largely because of widespread fundamentalism and the politicization of science in the United States,one in three American adults firmly rejects the concept of evolution,a significantly higher proportion than found in any western European country. Acceptance is slightly higher among Americans with some college education, with 49\% 
accepting evolution for plants and non-human animals (but only $22 \%$ accept human evolution) [3].

Gibson \& Hoefnagels [4] investigated the relationship between introductory biology students' tree-thinking skills and their acceptance of evolution,to determine whether using tree thinking as an organizing framework throughout an introductory-level course can improve students' acceptance of evolution as a valid, scientific theory that unifies a diverse array of empirical evidence and provides a foundation for all areas of biology. The present study identified a significant relationship between students' tree thinking and their acceptance of evolution.

Evolution is a process of nested descent with modification, with lineages diverging from common ancestors and producing the branching patterns of phylogenetic trees [4]. Phylogenetic Systematics is the field of study developed to understand the evolutionary history of organisms, traits, and genes. Tree-thinking is the term by which we identify concepts related to the evolutionary history of organisms. It is vital that those who undertake a study of biology be able to understand and interpret what information these phylogenies are meant to convey [5]. The ability to understand and reason with tree of life diagrams (i.e., cladograms), referred to as tree thinking, is an essential skill for biology students [6]. Tree thinking is the ability to visualize evolution in tree form and to use tree diagrams to communicate and analyze evolutionary phenomena. Tree thinking is essential for developing an accurate understanding of evolution and also helps one to organize knowledge of biological diversity [7].

Novick et al. [8] identified five core tree-thinking skills that are essential for understanding and reasoning with cladograms: (1) identifying characters (i.e., synapomorphies) that are inherited from a most recent common ancestor (MRCA) and shared by two or more taxa, (2) identifying a set of taxa that either do or do not share a specific character, (3) understanding the concept of a clade or monophyletic group (i.e., a group comprising an MRCA and all of its descendants), (4) evaluating relative evolutionary relatedness among a set of taxa, and (5) using evidence of most recent common ancestry to support inferences.

The TTCI (Tree Thinking Concept Inventory) is a multiple choice instrument that measures student s' understanding of phylogenetic trees. TTCI is a measure of concept inventory of the student's answers to the questions that given [9]. The importance of understanding evolution by those who study the origins, diversification and diversity life cannot be overstated [5]. Unfortunately, the theory of evolution that many taught to students more using animal models. In evolutionary learning can use animal and plant models to understand of evolution with phylogenetics diagram.

\section{Methodology}

The method of the research is descriptive qualitative. The sample in this study was undergraduate student's enrolled in an evolutionary course for biology majors at an Universitas Pendidikan Indonesia (UPI) Bandung, taken by purposive random sampling technique by the reason based on phylogenetics on students' competence. In this study, 
I used the Tree Thinking Concept Inventory (TTCI) modified instrument by [10] are objective test in multiple choice question which in students can select five options in every question and the form of a questionnaire that contains 15 statements as a Non-test instrument to describe a student response tree thinking understanding in the learning of evolution with Yes or No as the selected answers. Data analysis using Microsoft Excel 2013 and software SPSS version 22 following is analysis content validity (TTCI test), question item validity (correlation product moment test), reliability using correlation product moment test, item difficulty level, to know the quality of research instrument.

\section{Result and discussion}

Analyzed the test result of1.1 using the modified Tree Thinking Concept Inventory (TTCI) to measure student's understanding of phylogenetic trees. On the table below presents the Percentage comprehension levels of Students' Tree Thinking Concept Inventory (TTCI).

Tabel 1. Percentage Comprehension Levels of Students' Tree Thinking Concept Inventory (TTCI) modified by Naegle's (2009)

\begin{tabular}{|c|c|c|c|c|}
\hline \multirow[t]{2}{*}{ No. } & \multirow[t]{2}{*}{ Sub Concept } & \multirow[t]{2}{*}{ Concept Indicator } & \multicolumn{2}{|c|}{ Percentage } \\
\hline & & & Animal models & $\begin{array}{l}\text { Plant } \\
\text { models }\end{array}$ \\
\hline \multirow[t]{2}{*}{1.} & \multirow{2}{*}{$\begin{array}{l}\text { Identifying characters } \\
\text { (i.e., synapomorphies) } \\
\text { inherited from a most } \\
\text { recent common } \\
\text { ancestor } \\
\text { (MRCA) and shared by } \\
\text { two or more taxa }\end{array}$} & $\begin{array}{lr}\text { Analyzing } & \text { characters } \\
\text { (synapomorphies) } & \text { derived } \\
\text { from a common } & \text { ancestor } \\
\text { organisms } & \end{array}$ & $95 \%$ & $40 \%$ \\
\hline & & $\begin{array}{l}\text { Diagnosing characters } \\
\text { (synapomorphies) based on } \\
\text { kinship descended from } \\
\text { ancestors organisms }\end{array}$ & $35 \%$ & $30 \%$ \\
\hline \multirow[t]{3}{*}{2.} & \multirow{3}{*}{$\begin{array}{l}\text { Identifying } \\
\text { set of taxa that either do } \\
\text { or do not share a } \\
\text { specific character }\end{array}$} & $\begin{array}{l}\text { Analyzing the relationship } \\
\text { of kinship among organisms }\end{array}$ & $70 \%$ & $65 \%$ \\
\hline & & $\begin{array}{l}\text { Comparing the } \\
\text { phylogenetics tree diagram } \\
\text { with two organisms }\end{array}$ & $35 \%$ & $40 \%$ \\
\hline & & $\begin{array}{l}\text { Describing the kinship } \\
\text { living organisms is } \\
\text { determined based on a } \\
\text { branching point (node) }\end{array}$ & $50 \%$ & $55 \%$ \\
\hline \multirow[t]{2}{*}{3.} & \multirow[t]{2}{*}{$\begin{array}{lr}\text { Understanding } & \text { the } \\
\text { concept of a clade or } \\
\text { monophyletic } r \text { group } \\
\text { (i.e., a } r \text { group } \\
\text { comprising a MRCA } \\
\text { and all of its } \\
\begin{array}{ll}\text { descendants), } & \end{array}\end{array}$} & $\begin{array}{l}\text { Analyzing the relationship } \\
\text { of kinship between the } \\
\text { Group (clade) of organisms } \\
\text { with a common ancestor } \\
\text { species and all its } \\
\text { descendants. }\end{array}$ & $80 \%$ & $80 \%$ \\
\hline & & $\begin{array}{l}\text { Determining kinship among } \\
\text { organisms that include sister } \\
\text { taxa }\end{array}$ & $55 \%$ & $15 \%$ \\
\hline
\end{tabular}




\begin{tabular}{|c|c|c|c|c|}
\hline \multirow[t]{2}{*}{ No. } & \multirow[t]{2}{*}{ Sub Concept } & \multirow[t]{2}{*}{ Concept Indicator } & \multicolumn{2}{|c|}{$\begin{array}{l}\text { Percentage } \\
\end{array}$} \\
\hline & & & Animal models & $\begin{array}{l}\text { Plant } \\
\text { models }\end{array}$ \\
\hline \multirow[t]{3}{*}{4.} & \multirow[t]{3}{*}{$\begin{array}{l}\text { Evaluating relative } \\
\text { evolutionary } \\
\text { relatedness among a set } \\
\text { of } \\
\text { taxa }\end{array}$} & $\begin{array}{l}\text { Comparing the two forms of } \\
\text { phylogenetic tree diagram } \\
\text { orientation of different } \\
\text { organisms (rectangular and } \\
\text { diagonal) based on } \\
\text { evolutionary history }\end{array}$ & $65 \%$ & $60 \%$ \\
\hline & & $\begin{array}{l}\text { Identifying the evolution of } \\
\text { organisms that show the } \\
\text { most primitive among other } \\
\text { organisms }\end{array}$ & $75 \%$ & $75 \%$ \\
\hline & & $\begin{array}{l}\text { Identifying the evolutionary } \\
\text { history of organisms that } \\
\text { show the results of the most } \\
\text { advanced evolution }\end{array}$ & $90 \%$ & $100 \%$ \\
\hline \multirow[t]{2}{*}{5.} & \multirow[t]{2}{*}{$\begin{array}{l}\text { Using evidence of most } \\
\text { recent common } \\
\text { ancestry } \\
\text { to support inferences }\end{array}$} & $\begin{array}{l}\text { Studying the evolutionary } \\
\text { history of organisms } \\
\text { through phylogenetic tree } \\
\text { diagram }\end{array}$ & $60 \%$ & $60 \%$ \\
\hline & & $\begin{array}{l}\text { Represents the shared } \\
\text { ancestor of the lineage of } \\
\text { organisms through } \\
\text { phylogenetic tree diagram }\end{array}$ & $55 \%$ & $40 \%$ \\
\hline
\end{tabular}

Based on the data analysis of objective test using the instrument of modified TTCI showed that there are a lot of students who have students greater percentage of the ability of tree thinking using animal models compared to plant models. Figure 1 below shows the percentage of comprehension levels with TTCI as a whole.

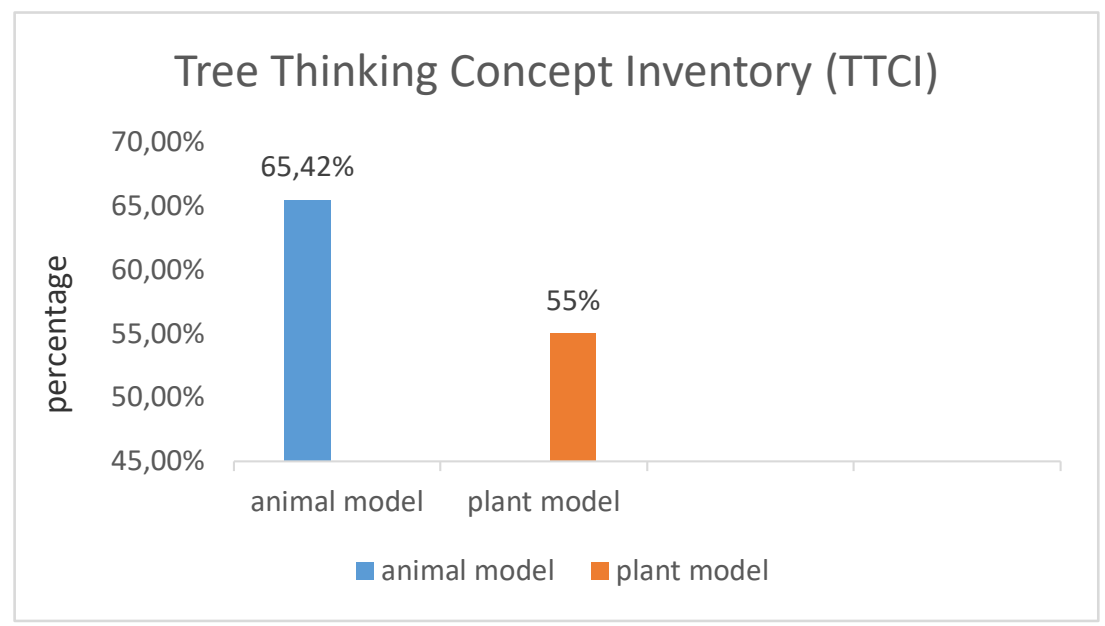

Figure 1. Tree Thinking Concept Inventory uses animal and plants model 


\subsection{Identifying characters (i.e., synapomorphies) that are inherited from a most recent common ancestor (MRCA) and shared by two or more taxa.}

This outcome requires that a student understand that the tree graphic depicts which characters a given taxon or taxa have and that the character inherited from a common ancestors [11]. According to the table 1, can be seen that concept indicator: Analyzing characters (synapomorphies) derived from a common ancestor organisms and Diagnosing characters (synapomorphies) based on kinship descended from ancestors organisms, show that animal models $(95 \%, 35 \%)$ are higher than the plant models $(40 \%$, $30 \%$ ). A learning objective that would go along with this learning objective is to ask students to identify all the characters a taxon from the tree would have. This objective would expand the expectation from the student by requiring them to interpret an entire lineage from beginning to end. Without the ability to interpret which characters have been passed on from common ancestors students are not able to make inferences about the evolution of these characters and taxa, which makes the mapping of characters on a tree uninformative [5]. Students are better at identifying characters using animal models, compared to plant models.

\subsection{Identifying a set of taxa that either do or do not share a specific character}

Students need to be able to distinguish between characters that reflect natural (based on evolutionary history) groups and those that do not, e.g., convergent characters [5]. According to the table 1, can be seen that three concept indicator. Concept indicator: Analyzing the relationship of kinship among organisms higher percentage of animal model results $(70 \%)$ than plant model $(65 \%)$, but 2 other concept indicator that is Comparing the phylogenetics tree diagram with two organisms dan Describing the kinship living organisms is determined based on a branching point (node) Resulting in a higher percentage of plant model than using animal models (40\%, 55\%).

\subsection{Understanding the concept of a clade or monophyletic group (i.e., a group comprising a MRCA and all of its descendants)}

So, sub concept above divided into two concept indicators that is Analyzing the relationship of kinship between the Group (clade) of organisms with a common ancestor species and all its descendants and Determining kinship among organisms that include sister taxa. Resulting in a higher percentage of animals model than using plant models $(80 \%, 55 \%)$. Understanding the concept of a clade is critical to proper interpretation of groups based on evolutionary history. A monophyletic taxon includes the most recent common ancestor of a group of organisms, and all of its descendants [12] while polyphyletic or paraphyletic groups do not reflect any meaningful history [5].

\subsection{Evaluating relative evolutionary relatedness among a set of taxa}

According to the table 1, it can be seen that sub concept above is divided into three concept indicator that is: Comparing the two forms of phylogenetic tree diagram orientation of different organisms (rectangular and diagonal) based on evolutionary 
history, Identifying the evolution of organisms that show the most primitive among other organisms, and Identifying the evolutionary history of organisms that show the results of the most advanced evolution. Based on the percentage of TTCI results, the first concept indicator showed the results of the animal model $(65 \%)$ higher than the plant model $(60 \%)$, the second concept indicator showed that the animal and plant models produced the same percentage $(75 \%)$, while the third indicator concept showed the plant (100\%) Higher than animals (90\%). Based on the above sub concept, students must be able to compare the relatedness of taxa in to make necessary and important biological inferences with evolutionary trees. Evaluating the evolutionary relatedness between species is complicated in multiple ways [5].

\subsection{Using evidence of most recent common ancestry to support inferences}

Table 1 divides that sub concept into two concept indicator that is: Studying the evolutionary history of organisms through phylogenetic tree diagram and Represents the shared ancestor of the lineage of organisms through phylogenetic tree diagram. The first sub concept shows the model animal model and animal yields the same percentage (75\%), while the second indicator concept shows the animal model (55\%) is higher than the plant model (40\%). Making inferences about character changes or gene function is another valuable tool that evolutionary trees give researchers. This allows mapping characters to the tree and cases of homology and analogy to be distinguished. This has important implications when determining the evolution of a character and taxa [13].

The result shows as a whole that the tree thinking ability of students used animal models $(65.42 \%)$ is higher than plants model (55\%) as shown in Figure 1. These results indicate that the students are higher in value using animal models compared to plants. Because in evolutionary learning, more taught by using animals models, so students are more interested in studying the evolution in animals model, judging by the results of TTCI.

Biological evolution is a difficult concept to learn, as several people at the convocation emphasized. It involves complex biological mechanisms and time periods far beyond human experience. Even when students have finished a high school or college biology course, there is much more to learn about the subject. The difficulty of teaching evolution both complicates and invigorates research on evolution education. To present what is known and not known about the teaching and learning of evolution [7]. So, the tree thinking approach is a process done by using a phylogenetic tree image to help make it easier for students to understand the content of the material [14]. So, phylogenies and tree-thinking instruction can provide tools to bridge the gap between classic historical approaches to teaching evolution and the more traditional emphasis on natural selection and microevolutionary change [15]. However, having students learn about and use phylogenies is not trivial [16]. Students hold several misconceptions that prevent them from using phylogenies effectively and that present "fundamental barriers to understanding how evolution operates [17]. Therefore, in evolutionary learning can use tree thinking approach through a phylogenetic tree to facilitate students in learning 
evolution. Can be seen from the results of TTCI, students prefer animal models compared to plant models; teaching evolution in lectures can use this as a reference.

\section{Conclusion}

This study showed that students remain to prefer animal models (TTCI score $=65.42 \%$ ) compare to plant models (TTCI score $=55 \%$ ) to study evolution. The use of plant models, however, must be considered by the teachers or the lecturers to make evolution more understandable.

\section{Acknowledgements}

The authors would like to thank all those who have provided financial and moral support for this research.

\section{References}

[1] Hidayat, T 2017 Menggairahkan Pembelajaran Taksonomi Di Kelas Menggunakan Metode Fenetik. Retrieved: 20 Juni 2017

[2] Miller J D, Scott E C, and Okamoto S 2006 Science. 313 765-766

[3] Lovely E C, and Kendrick L C 2008 Integrative and Comparative Biology. 48 164-174

[4] [4] Gibson and Hoefnagels 2015 Evolution: Education and Outreach. 815

[5] Kummer T A 2017 Assessing and Improving Student Understanding of TreeThinking (Ph.D. dissertation) USA: Brigham Young University

[6] Philips C B, Novick L R., Catley K M., Funk D J 2012 Evolution: Education and Outreach. 5 595-602

[7] Baum D A and Smith S D 2013 Tree Thinking An Introduction to Phylogenetic Biology ' Ed Michael Ziegler' the United States: Roberts and Company Publishers, Inc 2

[8] Novick L R., Stull A T, Catley K M 2012 Bioscience 62 757-764

[9] Walter E M, Halverson K M, Boyce C J 2013 Evolution: Education and Outreach 626

[10] Naegle E 2009 Patterns of thinking about phylogenetic trees: A study of student learning and the potential of tree-thinking to improve comprehension of biological concepts (Ph.D. dissertation) Pocatello, ID: Idaho State University

[11] Catley K M, Phillips B C, and Novick L R 2013 Research in Science Education $432327-2348$

[12] Carr S M 2012 Concepts of monopoly, polyphyly, \& paraphyly Retrieved: 20 Juni 2017

[13] Eddy S L, Crowe A J, Wenderoth M P, and Freeman S 2013 Evolution: Education and Outreach 113

[14] Olson S, Rapporteur, Laov J 2012 Thinking Evolutionarily: Evolution Education Across the Life Sciences: Summary of a Convocation Washington (DC): 
National Academies Press (US)

[15] Smith J J, Cheruvelil K S, Uvenhine S A 2013 CBE—Life Sciences Education 12 $542-552$

[16] Meisel R P 2011 Evol Educ Outreach 3 621-628

[17] Meir E, Perry J, Herron J, Kingsolver J 2007 Am Biol Teach 69 71-76 